\title{
Exploring University-Community Collaborations
}

ELIZABETH KRYDER-REID, GABRIEL FILIPPELLI with PHYLLIS BOYD, PAULA BROOKS, AGHILAH NADARAJ, ALVIN SANGSUWANGUL, and LEAH HUMPHREY

\section{ABSTRACT}

The Riverside neighborhood bears multiple burdens of environmental harm. Running the gamut from groundwater contamination in subsurface waters to lead in soils and dust and paint to particulate matter in the air from highways and industry, these environmental insults harm the physical, mental, and economic well-being of the community. The community has also faced an information gap where data was scarce, hard to locate, and sometimes wrong. Activists have long worked to improve the quality of life in the neighborhood, but faced barriers in the form of policies (e.g. Red Lining, zoning variances, disinvestment in public services such as street lights and sidewalks) and practices (e.g. absentee landlords, illegal dumping). Features such as the Central Canal that were developed into recreational amenities in other parts of the city were minimally maintained or restricted from use by residents. In the face of these challenges, IUPUI faculty, students, and community members have partnered on multiple projects to document the history of environmental harms, assess exposure and risk of residents' exposomes, and share information in ways that are accessible and relevant for residents. The work supports the agency and activism of the community, particularly as it faces pressures of gentrification and university encroachment with the prospect of 16 Tech project expansion. The work also takes place in the context of contested interests and harmful legacies as representatives of an urban university that displaced longtime residents work to partner ethically and transparently with those same communities. As a result, current faculty-community collaborations operate within a space complicated 
by the problematic legacy of harm and ongoing structural racism. However well-intentioned, faculty, students and community members have to navigate that history and enduring power dynamics as they design their research, identify relevant questions, and share results in ways that are accessible and meaningful to community members.

\section{INTRODUCTION}

University-community collaborations are complicated, and when tackling environmental justice issues, they can be particularly difficult. This essay explores some of the challenges and benefits of two community engaged environmental justice projects from the perspective of IUPUI faculty members Elizabeth Kryder-Reid and Gabriel Filippelli in consultation with community partners, and drawing on insights from students involved in one of the projects. Both projects focus on the Riverside neighborhood, the area northwest of downtown Indianapolis and north of the expanding IUPUI campus. We begin with a discussion of the power dynamics of the collaboration and a brief introduction to the Riverside neighborhood. We then share two projects as case studies to illuminate the potential and problematics of environmental justice collaborations between a large urban university and small, non-profit advocacy organizations.

IUPUI's commitment to community engagement presumes that there is an exchange of value in community-based teaching and research. The faculty who invest in community-engaged work recognize the time and energy it takes to build relationships and trust with partners. They accept the work it takes to produce results that are accessible to community members, whether that is sharing the work in community forums or developing digital tools that expand public access to data. Community partners who enter into collaborations with IUPUI know full well the institution's history of displacement and the asymmetry of budgets, staff, and other metrics that are typically commensurate with institutional power.

Within higher education, community-engaged projects are understood to be fraught with disparities of access, authority, and accountability. Scholars studying community engagement have mapped the exchange values on trajectories of transactional to transformative (Bringle, Clayton, and Price 2009; Dumlao 2018) and debated the merits of tactical versus strategic partnerships (Feigenbaum 2010 - 2011, Mathieu 2005, 2012, Parks 2009). Rachael Shah has proposed a conceptual framework of "critical community-based epistemologies" which posits that "community partners are holders and producers of powerful knowledge, and these knowledges can be invaluable in shaping engagement collaborations.” (Shah 2020: 107). She argues that this epistemology should both inform the "ethical vision that acknowledges the importance of community member voices, perspectives, and priorities" (109) and the power dynamics so that community partners can hold universities accountable. For IUPUI faculty, the value of community expertise is not only a fundamental principle, but a powerful driver of our motivations. Community partners' expertise and lived experience are a foundational knowledge base. At the same time, course-based projects

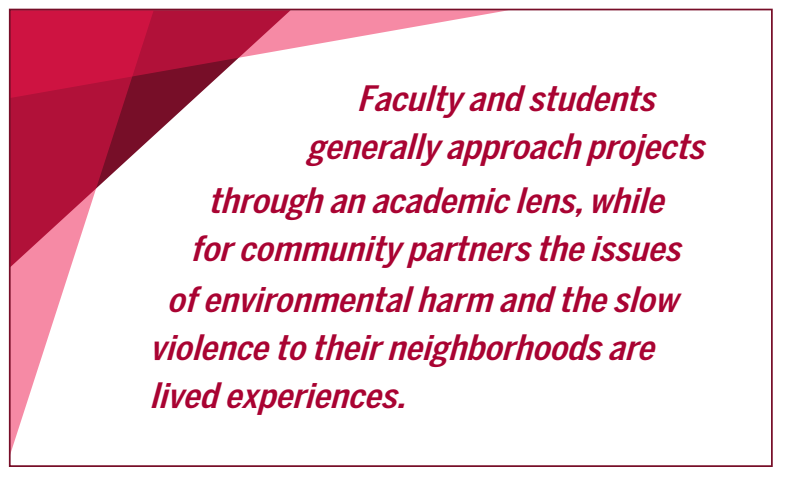


inherently align with university schedules, ways of working, and desired outputs and outcomes. They are, therefore, often not in sync with community partners' many obligations, priorities, ways of knowing and working. At a pragmatic level, faculty are paid to teach and do research, and it is both expected and in our professional interest to produce scholarship about our work (such as this article). For community partners, the time to meet, write, edit, and respond to requests for information is unpaid labor that comes on top of the already heavy loads of frontline community development, advocacy, and social justice work.

There is often an asymmetry or divergence at an emotional level as well. Faculty and students generally approach projects through an academic lens, while for community partners the issues of environmental harm and the slow violence to their neighborhoods are lived experiences. They are a part of generations of racialized environmental trauma, and the impact to their communities' social, physical, and financial health is personal. Finally, the difference is also often about epistemology, paradigms, and assumptions. The university-trained faculty and students are prepared to frame a problem (hopefully one that is relevant to the community), design a methodology, collect data, analyze the data, and share the results. While that research paradigm has its merits, it also frames the entire enterprise in terms of a problem. It leaves little room to celebrate community agency, resilience, and creative problem solving. It often also leaves little space for deep listening to understand the concerns and perspectives, the joys and curiosities, the hopes and fears of community members. The objectivity and rationality that is the scholarly mode of being can be crippling in a project that hinges on building empathy and centering community voices. It also often privileges the observable, material, and tangible, and fails to account for the intangible heritage of lived experiences and oral traditions. It often focuses on objects and outputs, and fails to attend to the relationships and social capital that are central concerns of the community.

\section{RIVERSIDE NEIGHBORHOOD}

The Riverside neighborhood is on the Near Westside of Indianapolis bounded on the north by 30th Street and the south by 16th Street, to the west by the White River and to the east by West Street/MLK. It has many attractive features including Riverside Park (Fig. 1), historic architecture, and a landscape design plan dating to the early 20th century in keeping with the City Beautiful urban planning principles.
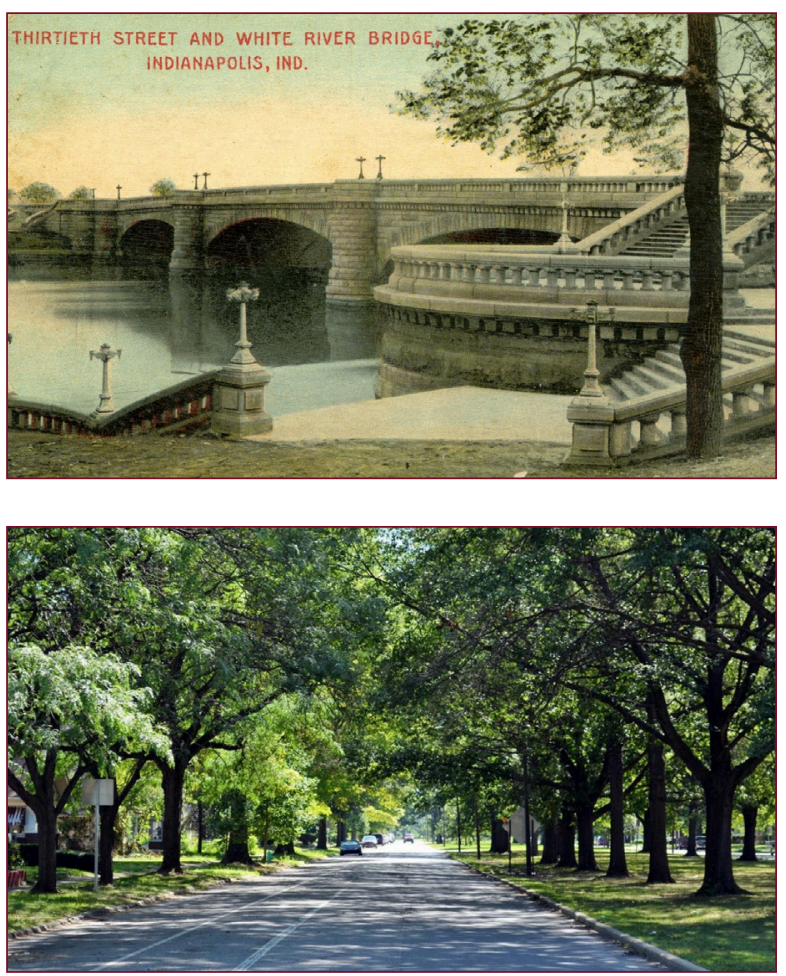

Fig. 2. Burdsal Parkway Photo by Marc Ancel, 2017, courtesy of The Cultural Landscape Foundation Fig. 1.

Postcard view of the 30th Street bridge over the White River and part of the Riverside Park landscape design Courtesy of E. Kryder-Reid 


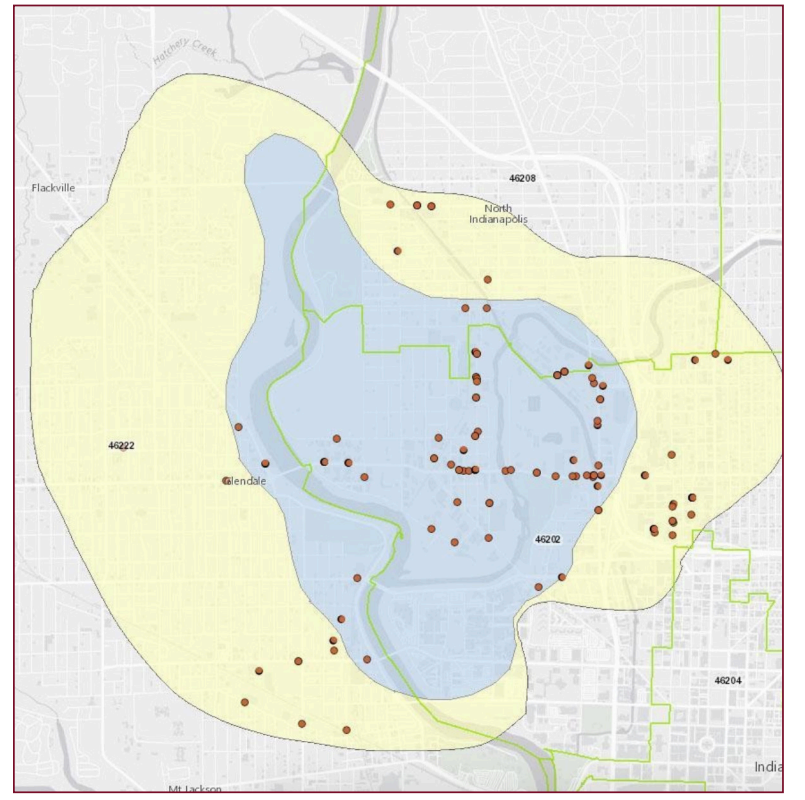

Fig. 3. Map of Site 0153 showing locations of potential responsible parties for the source of the groundwater contamination Courtesy of IDEM

Portions of the design, including Burdsal Parkway (Fig. 2), a wide east-west boulevard designed by George E. Kessler (1909) with a central median planted with grass and mature shade trees, contribute to the Riverside Drive Historic District. While primarily residential with a long-standing African-American community, the neighborhood also has a history of industrial and commercial sites, particularly along the Central Canal and the southeast area along 16th Street and Montcalm. The combination of industrial sites, dry cleaners, gas stations, the railroad, and the 165 Interstate (completed in 1976) have created a superfundeligible groundwater contamination site (Site 0153), and left a legacy of environmental burdens that current residents now bear (Fig. 3).

Running the gamut from groundwater contamination in subsurface waters to lead in soils and dust and paint to air pollution from highways and industry, these environmental insults harm the physical, mental, and economic well-being of the community. The community has also faced an information gap where data was scarce, hard to locate, and sometimes wrong. Activists have long worked to improve the quality of life in the neighborhood, but faced barriers in the form of policies (e.g. Red Lining (Fig. 4), zoning variances, disinvestment in public services such as street lights and sidewalks) and practices (e.g. absentee landlords, illegal dumping) (Schwier and Elliott 2014). Features such as the Central Canal that were developed into recreational amenities in other parts of the city were in the Riverside neighborhood minimally maintained or restricted from use by residents.

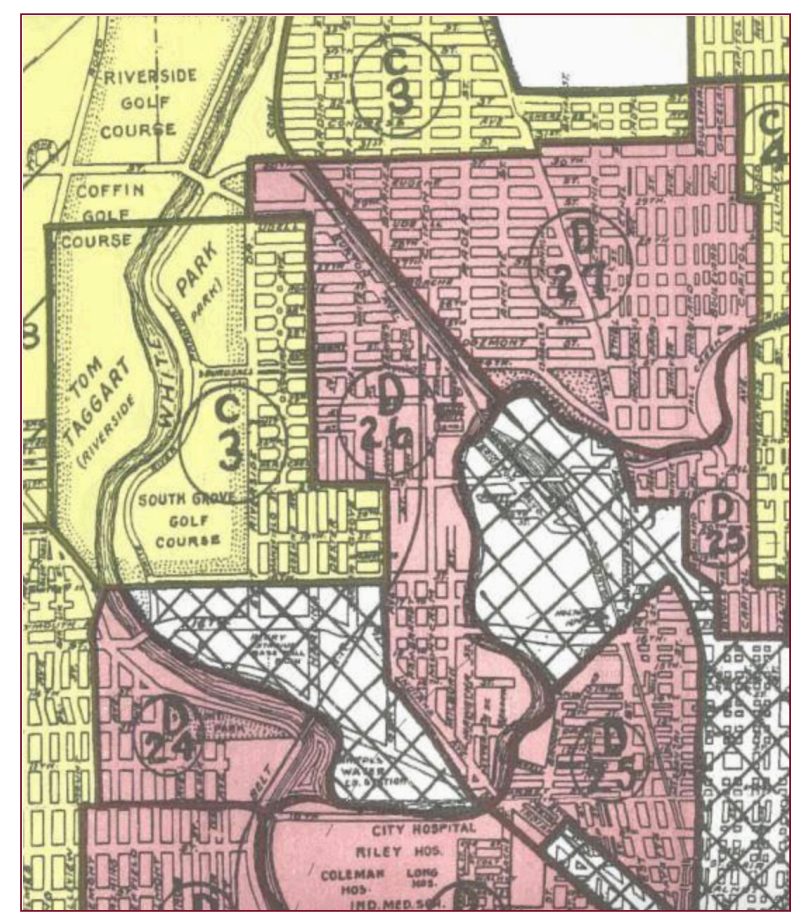

Fig. 4. Riverside Neighborhood, detail of the 1937 Home Owners Loan Corporation (HOLC) map indicating in red the areas that were at "high risk" for loans based on the residents' demographics and excluding areas with African-Americans from eligibility for government loans. 


\section{PROJECTS}

In the face of these challenges, IUPUI faculty, students, and community members have partnered on multiple projects to document the history of environmental harms, assess exposure and risk of residents' exposomes, share information in ways that are accessible and relevant for residents, and create public humanities projects that share the history of the area and create broader awareness of the environmental issues and the systemic environmental racism that has exacerbated them. The work supports the agency and activism of the community members, particularly as they face pressures of gentrification and university encroachment with the planned 16 Tech project expansion. We share two of these projects as case studies to offer insights into communitycollaborative environmental justice research.

\section{Case Study 1: Lead Exposure}

The Center for Urban Health at IUPUI has a long history of conducting community-driven work in identifying and eradicating sources of the harmful toxin lead in the environment, and thus improving community health. This work has largely focused on soil-based risks, as much of the lead used in the 20th century in leaded gasoline, lead-based paints, and emitted from industrial sources accumulated and concentrated in surface soils. More recently, the Center has built on the citizen-science approaches, in which data is collected by members of the public, by adding indoor dust measurements to its toolkit of exposure monitoring resources, and in 2021 added indoor tap water as another indicator. Collectively the science, educational, and outreach aspects of these efforts have been captured in the global citizen-science platform www.MapMyEnvironment.com. This resource is a "one-stop shop" for exploring community-based work on the human environmental exposome, and is meant to be adaptable and scale-able to continue adding new functions and layers as more results and more indicators come into play.

Barriers to participation in such a program includes (1) a community member's knowledge of this resource, (2) overcoming the "participation cost" which often includes materials and postage, and (3) concerns about liability and anonymity of home-based environmental data. To overcome some of those barriers, the Center for Urban Health partnered with the IUPUI Arts and Humanities Institute (IAHI) and a local collaboration of congregations under the Ministerium to conduct a unique and highly geographically focused project to educate on hazards, distribute and collect kits from participants, and deliver results back to participants in an anonymous manner. In this current partnership, the Ministerium plays a central role as the public face of the program, and the university partners play the role of kit development, analytical services, and research translation.

This "community-forward" approach was successfully carried out in an earlier partnership between the Center for Urban Health and Groundwork Indy, focusing on soil lead hazards in the Riverside neighborhood of Indianapolis. This partnership involved the Center for Urban Health augmenting the normal youth leadership development programs at Groundwork by funding several additional youth as "Environmental Justice Fellows" and educating a cohort of the students as lead experts. This involved providing some background information about lead and lead in their community, introducing them to the university and the laboratory where the analyses would be conducted, an eye-opening experience for those who had not set foot on a college campus before. The cohort also gathered to discuss how they were going to implement detailed soil sampling efforts. The youth then became the leads 

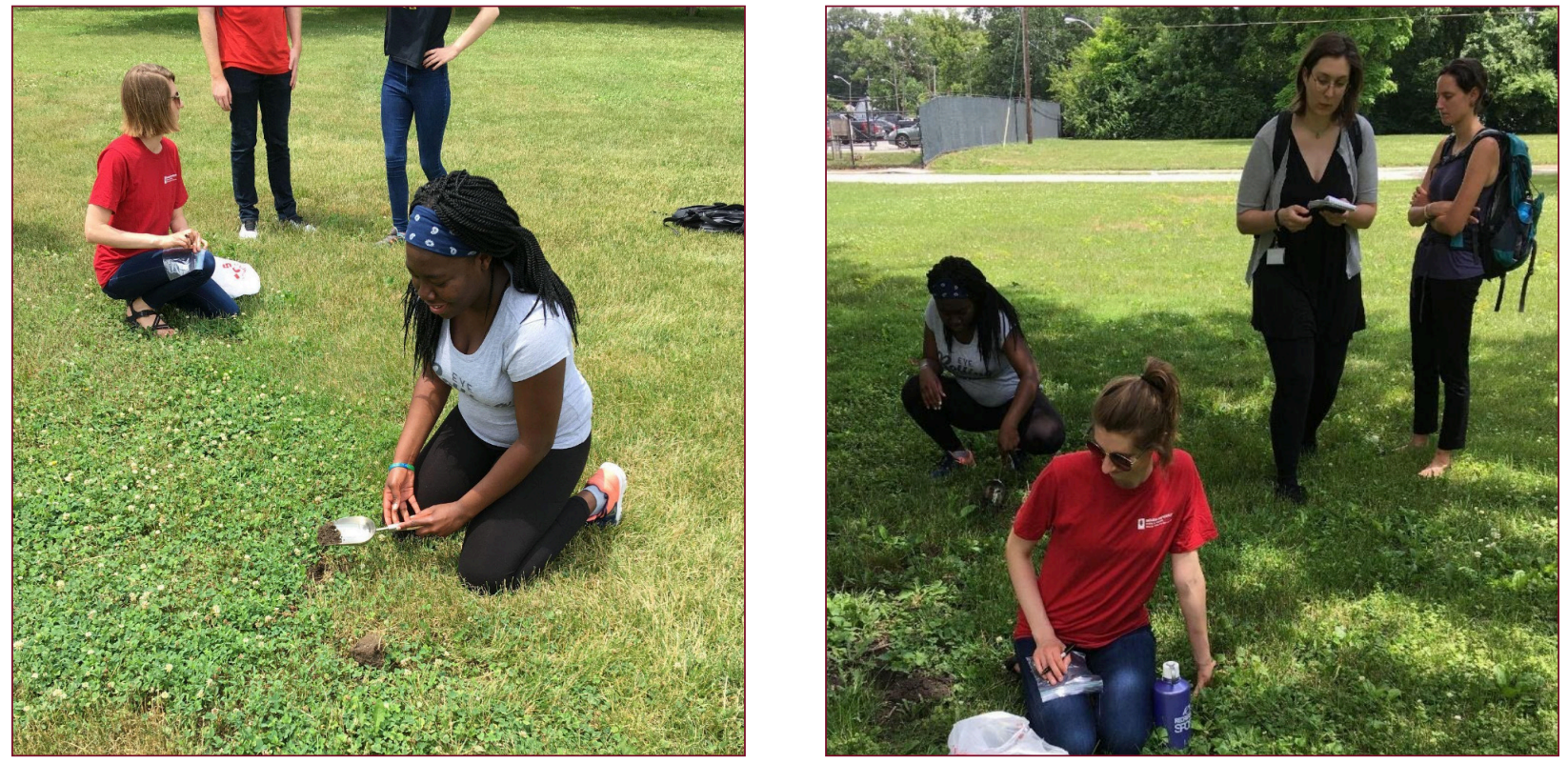

Fig. 5, 6. Youth members of the Keep Indianapolis Beautiful Green Tree Team and IUPUI students sampling soils at the JVT Park in the Martindale-Brightwood neighborhood of Indianapolis for lead analysis.

of the program, discussing with residents what they were trying to do, conducting sampling of occupied and vacant properties, collecting the samples centrally, and then translating-relaying results back to occupants and answering questions (Figs. 5, 6). Groundwork Indy executive director Phyllis Boyd explained that part of the goal for the youth participants is to help them see themselves as agents of change. Working as part of the "Green Team" engages them "in the process of how you think and dream about spaces and how you can change them ... so they get to see the whole arc of how you as a person can do stuff in the world" (Boyd quoted in Yousry 2021).

Two revelations emerged from this program, exemplifying the importance of community participants having leadership and agency in citizen science projects. The first involved recruitment. Many residents were wary of anyone knocking on their door and asking about their property, as they had been victims of predatory real estate agents and other unsolicited visitors. The youth decided it was going to be more efficient to make a door hanger explaining the program and providing a contact number for the residents to call should they want to participate. The youth then went to those homes wearing Groundwork Indy shirts and a program badge, and had few problems with the sampling.

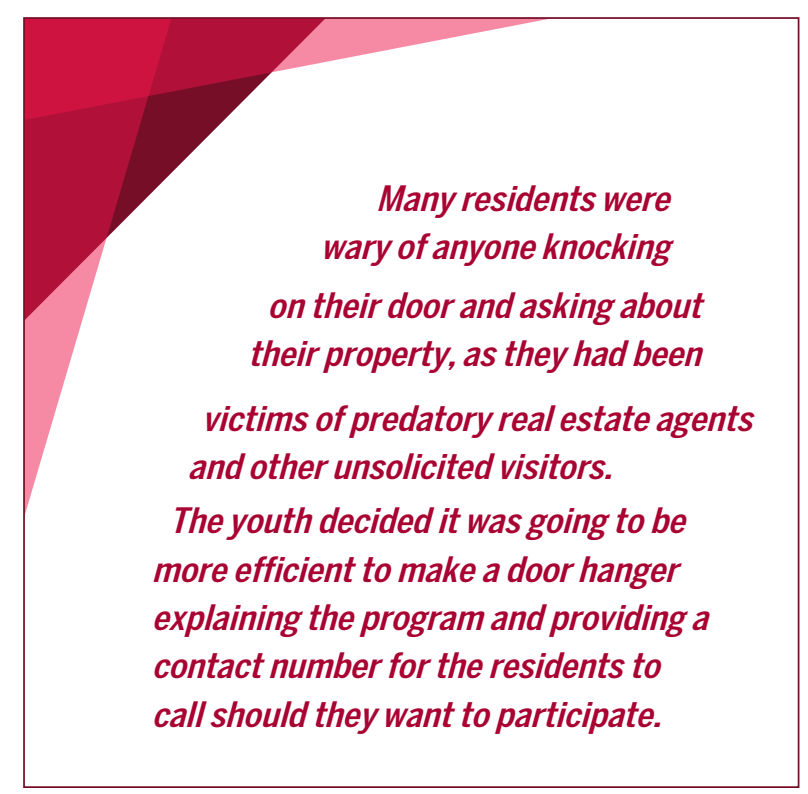


The second revelation involved unlicensed day care settings. In some of the introductory discussions, Center for Urban Health staff noted that many of the residents would likely have high soil lead values, and given the risk to children of lead poisoning, that day care centers were a particular concern. But because many day care centers in the area were unlicensed, they did not have soil lead testing and thus could pose risks to the children. Furthermore, Center staff noted that soil lead was typically a very easy problem to solve if you know it's an issue, as an intervention as simple as adding a thick layer of mulch solves the soil exposure problem immediately. The youth took these kernels of information, and, unbeknownst to Center staff, devised an incredibly creative solution. Groundwork had trucks and the ability to provide free mulch, so the youth held beautification days, where they approached the day cares and offered to do landscaping, including adding thick mulch in and around outdoor playgrounds. All of the day cares approached were thrilled about this, and the youth coordinated the "capping and covering" of properties, without even mentioning the word "lead" to the day care facilities. In a perfect world, the facilities would be aware of and have already protected children in their care from lead exposure, but in a practical world the Groundwork youth managed an intervention that Center for Urban Health staff never would have considered, given their focus on the science side of the problem rather than the solutions side.

\section{Case Study 2: Climates of Inequality}

From 2017-2021 IUPUI faculty and students in Museum Studies and Public History, along with Kheprw Institute (KI) and other community partners, had a remarkable opportunity to collaborate on a project focused on environmental justice in Indianapolis' urban core. ${ }^{1}$ Together, we investigated the history of the city's public waterways to develop a range of environmental humanities projects designed to engage broad publics in the history of environmental harm and its effects on the cities' neighborhoods, particularly communities of color and lower socio-economic status. In three classes over three semesters, students worked with KI to develop research briefs, exhibits, digital humanities projects, social media, and public programs. (Climates of Inequality; Indy Environmental Justice History, Indy Environmental Justice History Facebook page, Toxic Heritage - Climates of Inequality project). KI team members were an integral part of the project (Fig. 7).

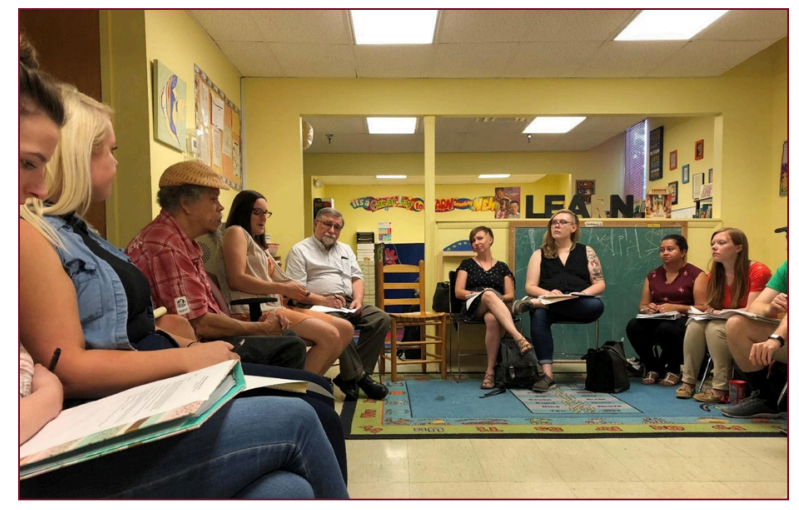

Fig. 7. IUPUI students, faculty, and KI leaders meet at $\mathrm{KI}$ in Fall 2018 for a conversation about Kl's environmental justice work and the principles of Just Transition.

\footnotetext{
${ }^{1}$ Kheprw Institute (KI) is a nonprofit organization focused on empowering youth and building community wealth in Indianapolis. Since 2003 , KI has worked to create a more just, equitable, human-centered world by nurturing youth and young adults to be leaders, critical thinkers and doers who see the people in any community as the most valuable assets and are committed to working with disinvested communities to bring about change that leads to empowered self-reliant and self-determining communities. For a more complete discussion of the COI project, see Kryder-Reid, Holzman, Nadaraj, and Humphrey, in press.
} 


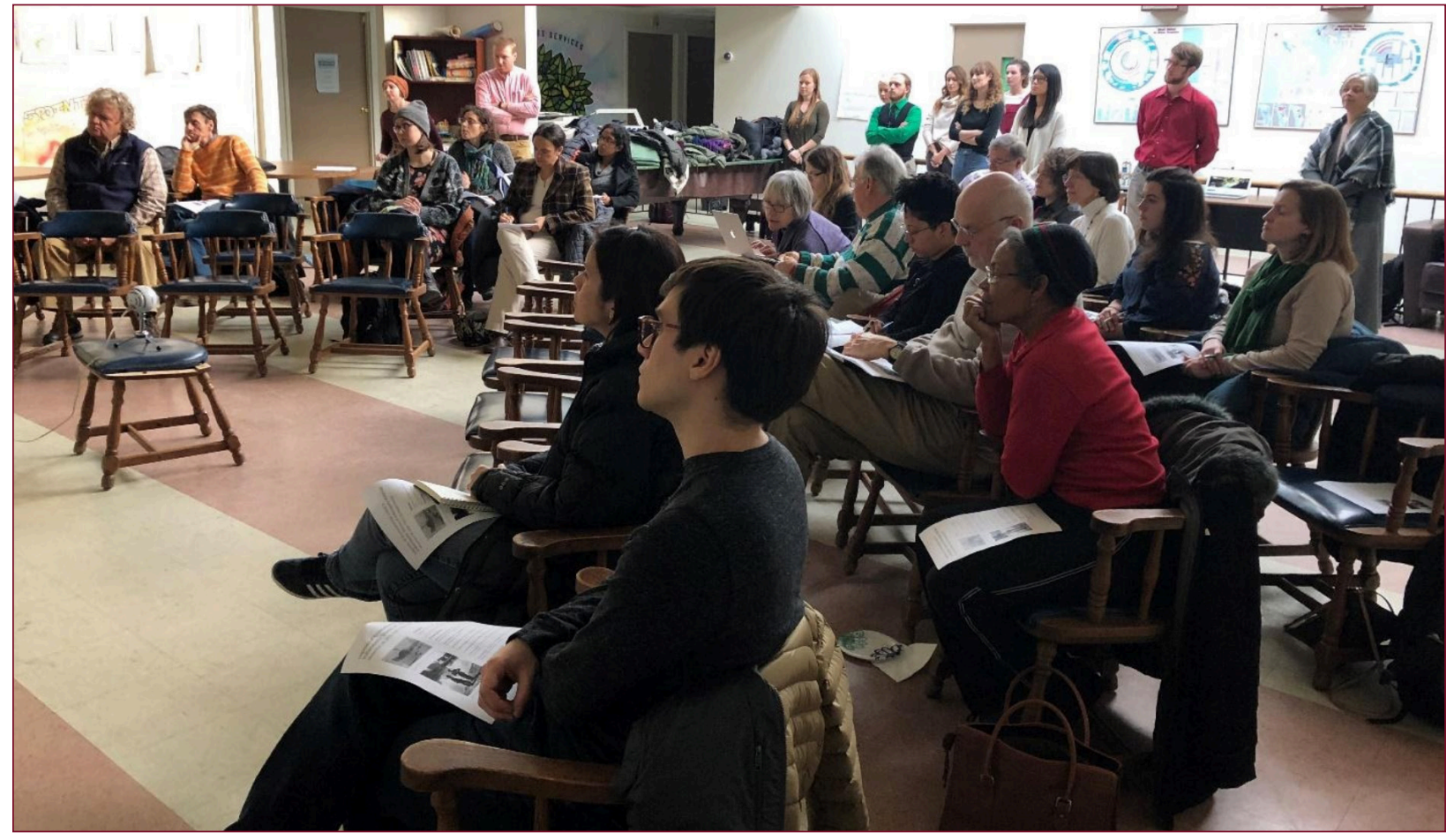

Fig. 8. Community members gathered at KI to see the presentation of the Climates of Inequality digital humanities projects developed by IUPUI students in Fall 2018.

They attended most of the classes, served as EJ subject experts, hosted community conversations, and led classes introducing students to the principles of Just Transition (Climate Justice Alliance 2016). They critiqued students' presentations of their research and project concepts, and they coached the students on engaging community organizations. They helped students identify people in the community to approach as informants and they filmed oral histories. KI also helped promote the public humanities projects by hosting a showcase of the digital humanities projects in 2018 (Fig. 8), promoting public programs, and speaking at the Climates of Inequality exhibit opening celebration (Fig. 9).

The project exemplifies some of the benefits and challenges of community-engaged teaching and research, particularly when focusing on issues of environmental justice. From the students' perspective, the learning experience was powerful because they were co-curating narratives with partners from KI and developing public-facing interpretive projects that spoke to pressing social issues.

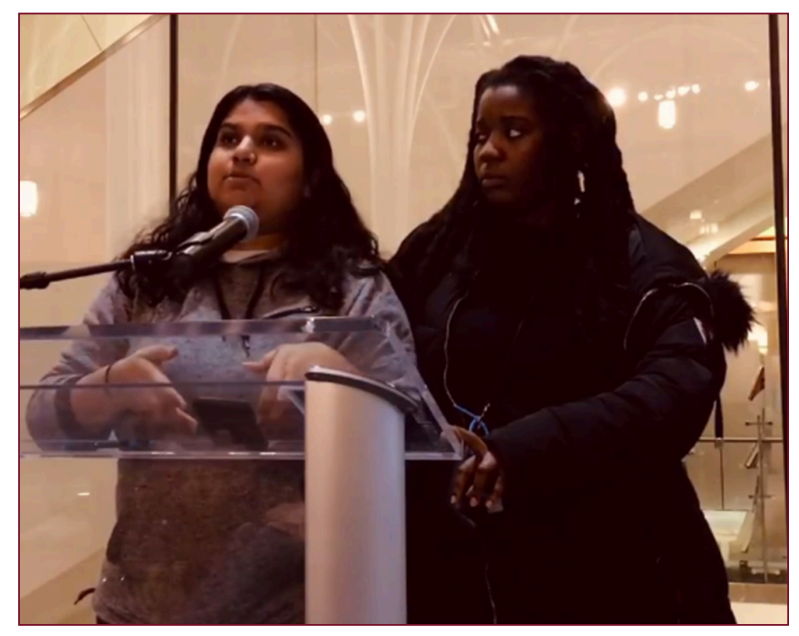

Fig. 9. Aghilah Nadaraj and Leah Humphrey speak at the opening of the Climates of Inequality exhibit at the Central Library, January 2020. 


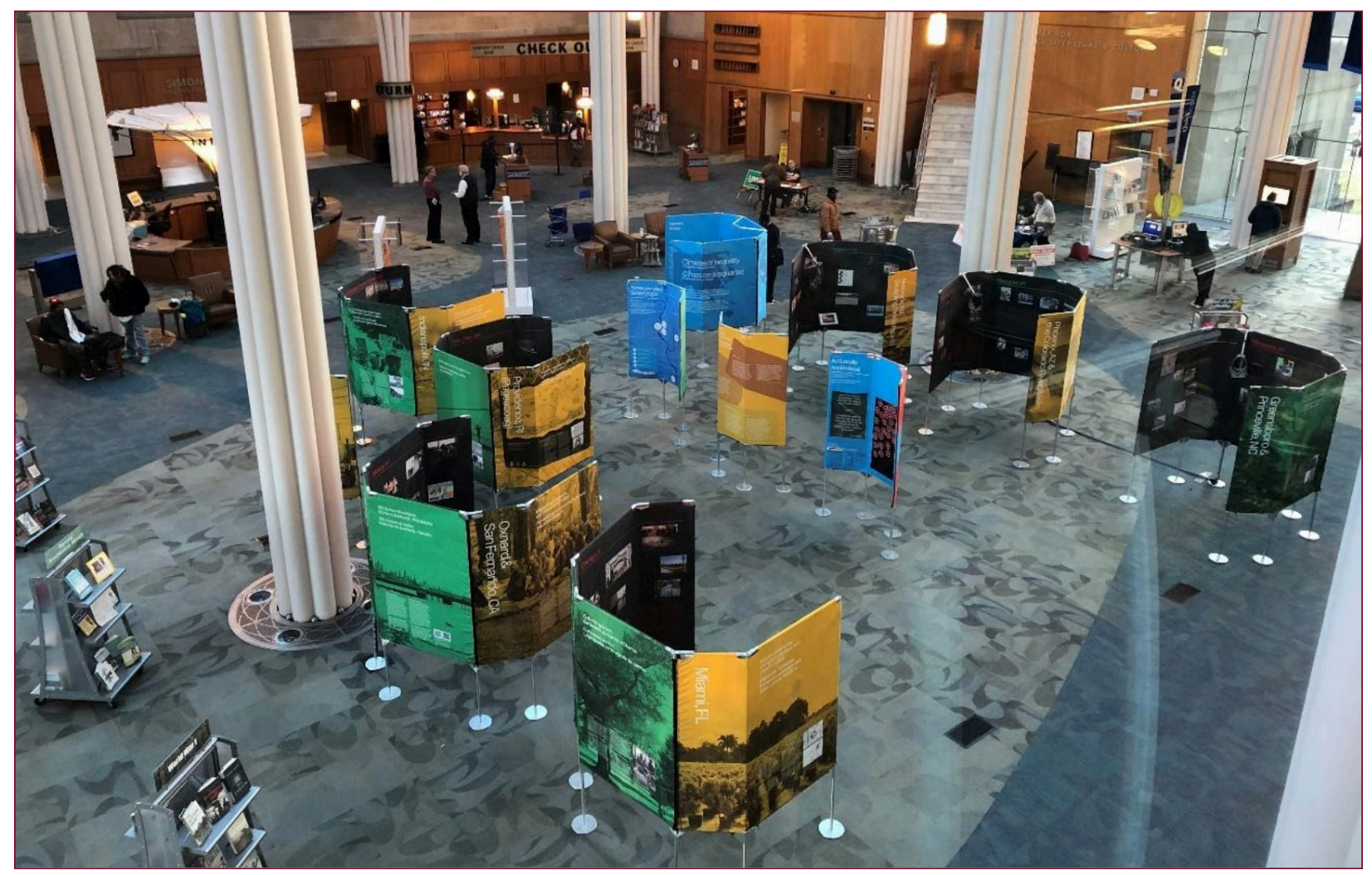

Fig. 10. Climates of Inequality exhibit, IMCPL Central Library, January 2020

A student wrote that she was excited "to see the project go from research to planning to finally execution ....The [exhibit] opening event allows us to see the interest that people have in this topic and that we are connecting with people and raising concerns through this work" (Fig. 10).

Students also appreciated making connections between the issues of environmental justice and their own lived experiences. For example, one student reflected,

"I've lived in the Indianapolis community for the past five years and prior to this course I can say I knew nothing of its history and issues. It made me recognize that it's important to really learn about where you reside and call home and to not be a robot who drives by Fall Creek Parkway every Saturday and Sunday but doesn't exert the effort it takes into finding out why it smells so horrible."
Other students valued the opportunity to build relationships with the KI team and other community leaders (Fig. 11), gain experience in community-focused collaborative projects, and build skills in public humanities practices (e.g. exhibit development, public programming, digital humanities).

At the same time, the ambitious scope and complexity of the project that was valued by some students was also problematic for many others

Museum Studies students had read deeply about museum history and its fraught legacy of exploitation and appropriation. They had read about decolonization (Lonetree 2012) and shared authority (Adair, Filene and Koloski 2011). Many had participated in projects that seek to address those histories of harm and are committed to the goals of partnerships that are not 


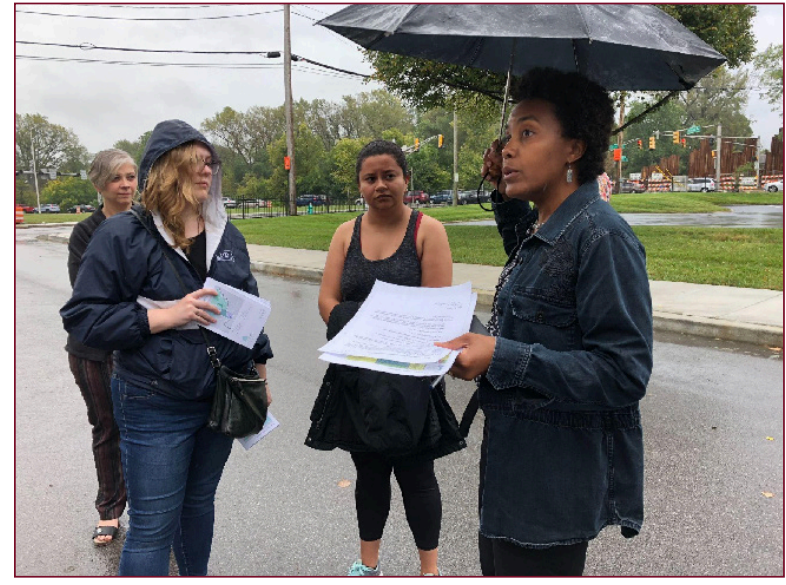

Fig. 11. Students in the research seminar tour Fall Creek with Mapleton Fall Creek Development Corporation CEO Leigh Riley Evans and Destination Fall Creek advocate Doug Day, Fall 2018.

merely transactional, but have the potential to be transformative. The gap between those goals and the realities of working on a course-based project for a semester were deeply troubling for some students.

Reflecting on the experience of working with the Kheprw Institute to investigate the history of Indianapolis' urban waterways through an environmental justice lens, some students wrote about their positive experiences as they learned, many for the first time, about the history of environmental harm and its disproportionate impact on communities of color. Others offered more problematic accounts of their experiences, particularly their discomfort with the perceived power dynamics of the university-community collaboration and their own positionality of privilege as graduate students and, in most cases, as white people.

- $\quad$ "I think that we did not address some ethical concerns with this project including coming off as a university trying to be 'white saviors' for the community."
- IIfound it difficult to reconcile with feeling like I was part of an exploitative university process that collaborates with marginalized community and then leaves. I did my best to get to know the KI members as individuals by meeting with them outside of class and attending their Facebook Live events. I often felt guilty during class when people, including myself, expressed uninformed views or made ignorant statements. I struggled to move past the feelings of guilt I had about how ignorant I am to the injustices marginalized communities experience and how I never felt like I had enough time to build deep relationships with community members."

- "It was also difficult to find community members even willing to communicate or share their experiences.... I do not blame the community for not wanting to work with students from an institution that has a harmful local legacy, but it was still frustrating nonetheless because I felt as though much of the content in the projects I was working on came too much from my 'outsider' perspective, and didn't include enough authentic community stories and perspectives."

- "Dialogue is important for me, because I hold collaboration, not consultation as an ethical standard for my curatorial practice when interpreting a community's experience. However, this ethical standard was difficult to adhere to with our single-semester time constraint and I do not feel that we were able to incorporate our community partner enough.... For me balancing my own ethics with expectations was the most challenging part of this course. I did not want to approach this project with a "white savior" lens or by dominating the narrative with my own authority and position of power." 

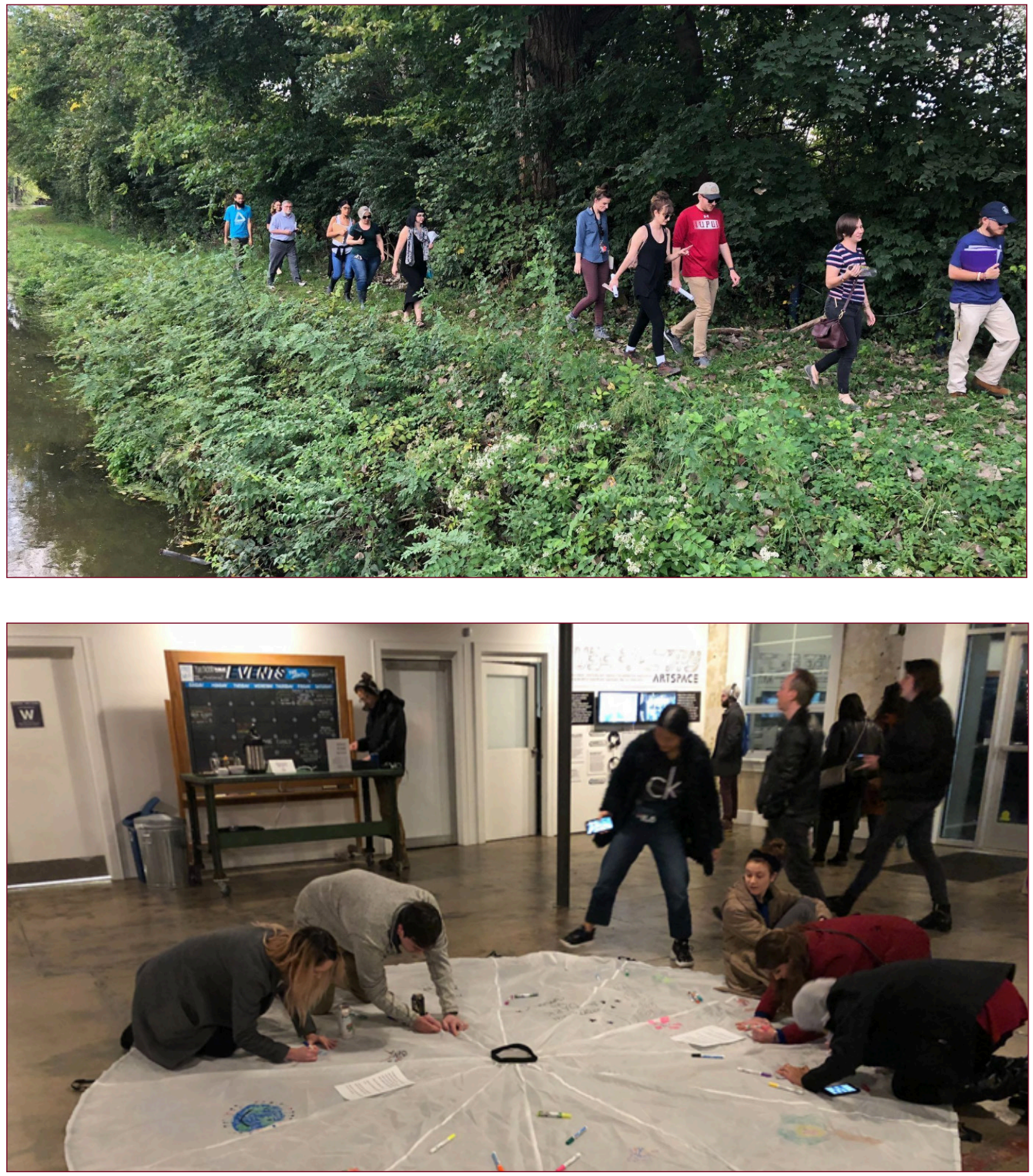

Fig. 12. Students learn about the Central Canal and the Riverside neighborhood on a walking tour led by Groundwork Indy Executive Director, Phyllis Boyd, Fall 2018. Fig. 13. “Parachuting into Environmental Justice," (top left) a public program developed by IUPUI Museum Studies students Hadia Shaikh and Sarah Shorter at Big Car Collaborative, January, 2020. 
As painful as these comments were to read, these students' reflections name many of the issues central to community-university collaborations and called into stark relief the difficulty of changing attitudes, let alone structures of power, through course-based experiences. Some students were inspired, but many were also discomforted or even paralyzed with their own privilege that they felt disqualified them from engaging in meaningful ways with community members or feeling like voyeurs on walking tours through affected communities (Fig. 12). The experience left many of the students with troubling questions about the possibilities of environmental humanities to affect real and lasting change.

In spite of these concerns, for some Museum Studies students, the project helped to shape their professional values in ways that may inform their entire careers. One student commented in a selfreflective essay, "I want my own professional work to be centered around community and making museums into places for community to be seen and heard." Another wrote that "I learned that true community collaboration means privileging your partner's voice and that museum professionals must act as an avenue to amplify that voice to new audiences....I am not always the content expert and ...I must defer to community voices to properly tell stories of social injustices....collaborative projects with community must be equitable and benefit the community partners as much as the museum" (Figs. 13, 14).

Another student wrote, "One of the most valuable parts of the class was the opportunity to grow my community collaboration skills including deep listening, active engagement, and genuine commitment. These skills will be foundational for my professional practice when I get a museum job."
For the community partners, particularly KI, the project produced historical and contemporary data as well as narratives that continue to benefit KI's work as they develop curriculum, provide context of current environmental harm, and curate other storytelling projects. The companion exhibit at the Central Library featured a spotlight on KI's work on environmental justice and two KI members spoke compellingly at the exhibit opening. These opportunities helped to raise awareness of KI's longstanding advocacy for community well-being.

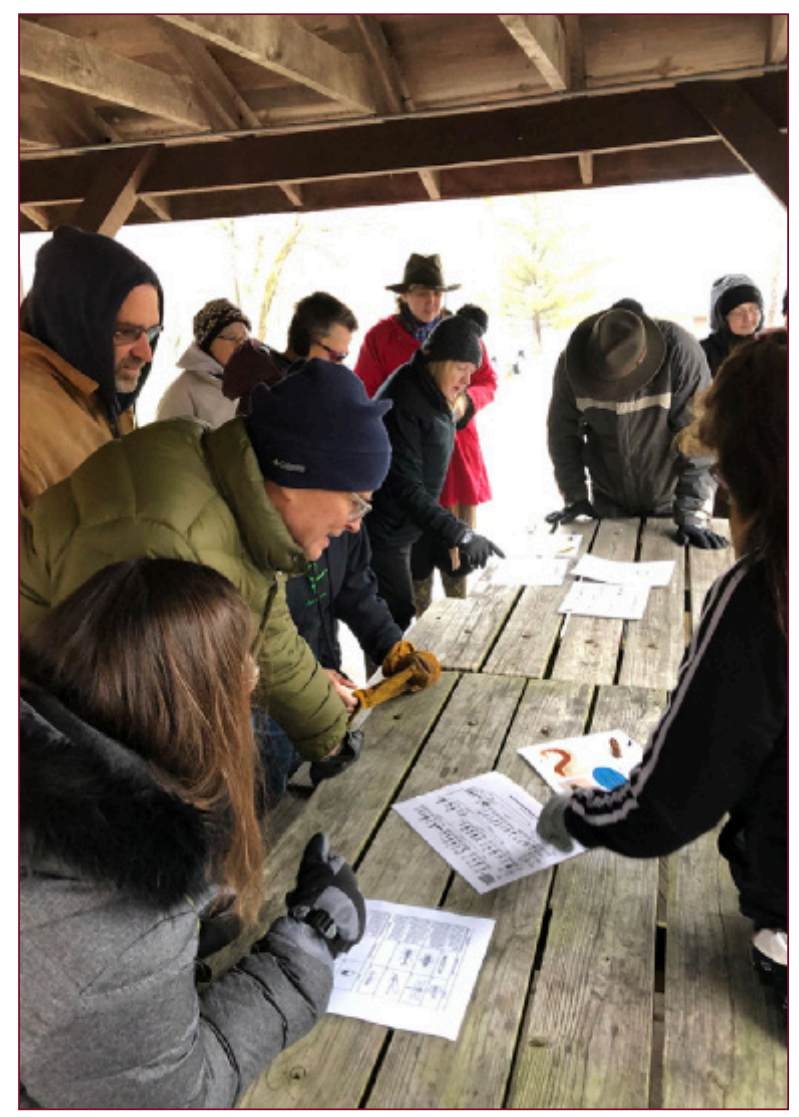

Fig. 14. "Follow the Fall Creek Flow" (left) public program developed by IUPUI Museum Studies student Megan Perry at Fort Benjamin Harrison Park, January, 2020. 
Furthermore, the project created opportunities for KI youth leaders to gain professional experience both in collaborating with the students and faculty and in participating in the Humanities Action Lab convenings at Newark University, Rutgers (Fig. 15).

In addition to the students' learning outcomes and the benefits for the Kheprw Institute, the project has also spurred additional research. IUPUI faculty collaborated on an IAHI-funded project exploring the "Social and Environmental History of Dry Cleaning," and the preliminary results have been disseminated in "Dirty Laundry" a fifteentweet Twitter thread (Kryder-Reid 2020) and "Environment and Race" a Story Map (KryderReid et al.). Elizabeth Kryder-Reid and Paula
Brooks, Environmental Justice Coordinator with the Hoosier Environmental Council, also presented a poster at the Society of Architectural Historians annual conference (and subsequently developed as a StoryMap) interrogating the persistence of environmental racism in Indianapolis. It drew parallels between the policies and discourse surrounding the construction of the combined sewer overflow system (CSOs) in the early 20th century and the site in the Riverside neighborhood proposed in 2018 to process gravel from the excavations for the replacement to the CSOs.

Working with Ms. Brooks and other community partners on these research projects has raised concerns similar to those expressed by students in the Climates of Inequality courses. While there

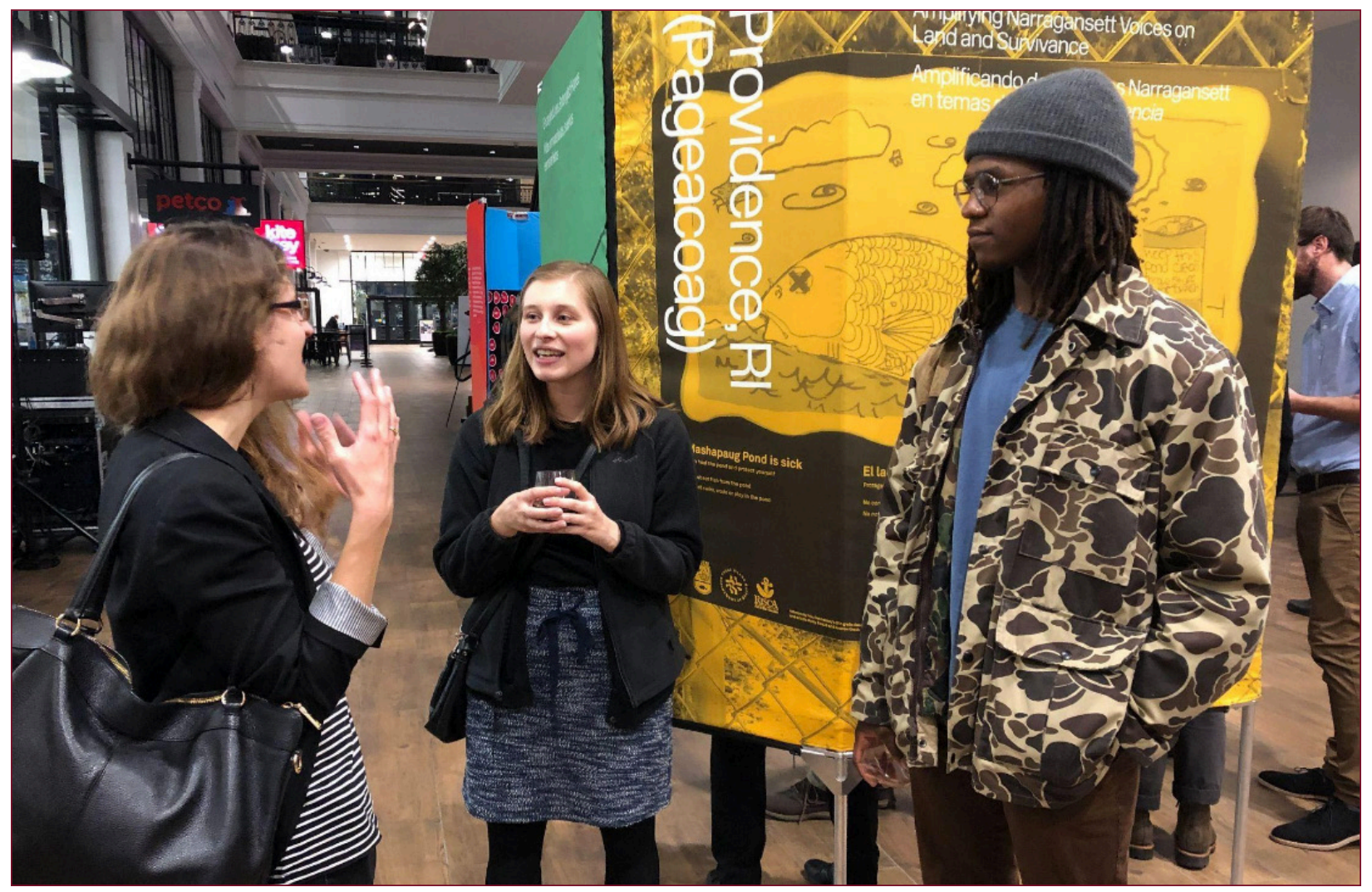

Fig. 15. Dr. Laura Holzman (IUPUI), Alisha Baginski (IUPUI), and Keenan Rhodes (Kheprw Institute) (right) attend the convening and exhibit opening of Climates of Inequality at Rutgers, Newark, October 2019. 
was benefit in conducting historical research and disseminating the results, it didn't minimize the University's past and ongoing harm related to the establishment of the IUPUI campus, the expansion into nearby neighborhoods, and the current development of Indiana Avenue and 16 Tech (Paschall 2020). In this time of racial reckoning, the University has made some gestures of atonement in the form of scholarships for displaced residents. Ms. Brooks, a third-generation resident of the adjoining Near Westside neighborhood most impacted by the university expansion, pointed out, however, that there was no apparent input from the people or the neighbors who were harmed. Despite the good intentions of such initiatives, the University has continued investing directly in development that is compounding the problematic impact on historical residents of the Near Westside, namely hostile architecture, disrupted connectivity, dangerous sidewalks and crossings, and increased traffic with its higher airborne particulate pollution as well as congestion and parking issues.

The project raised significant questions for faculty roles in community-engaged environmental justice work as well. In a conversation among the authors about the complex and often contested power dynamics of university-community collaborations, a community partner referred to the "four horsemen of gentrification.” Although seemingly flip, the comment called into question the roles the faculty were playing in these community collaborations focused on environmental justice. Were faculty complicit in the displacement and gentrification that communities were battling, despite the best intentioned citizen-science and purportedly activist scholarship? Were faculty merely documenting the historical and contemporary harm of environmental racism, inequity, and injustice, or were they working toward reparative and restorative justice? Or more troubling, by training a scholarly lens on environmental justice issues were faculty mounting one of the horsemen of gentrification, along with urban planners and landscape architects, to create an intellectually cohesive but aestheticized narrative that continued to marginalize or erase the real concerns of residents? How were faculty acknowledging the responsible people and institutions, along with the systemic forces that created the conditions, including the role of the University? Were faculty just narrating the history, or taking action to address the harm and create real, enduring change? There are no simple answers, and faculty and students must continue to bring critical and self-reflective lenses to this work (Shah 2020, Warren-Gordon 2021).

\section{Reflections on Community Engaged EJ Research and Teaching}

These two case studies exemplify the value of a multi-year projects with long-term shared institutional goals, the value of collaborative research shared in accessible formats, and the potential for using the city as an environmental justice classroom. Proponents of engaged teaching have suggested that long term partnerships can be more manageable and rewarding than short-term collaborations (ex. Jay 2012) and in ways that allow for not just tactical, but strategic goals (Feigenbaum 2010 - 2011, Mathieu 2005, 2012, Parks 2009). The COI project, which has taken four years including planning and dissemination, demonstrates both the results of a longer-term partnership and the challenges of spanning multiple courses and a changing cohorts of students.

The COI project in particular revealed the importance of process and structure for ensuring successful student learning outcomes and community partner satisfaction. In many ways these findings are most powerfully highlighted in the project's shortcomings. Rachael Shah's Rewrit- 
ing partnerships: community perspectives on community-based learning (2020) was published too late to inform the COI project, but it contains several concepts and resources that may be useful in future community engaged courses. The importance of self-reflection is well documented as a high impact practice, but assigning a weekly journal entry and requiring a final essay was clearly not sufficient to support some students' struggles to situate themselves in the project and its larger context of environmental justice. Shah offers an "openness huerisitic" which asks students to write a definition, provide 4 concrete examples, and offer a self-reflection on each of the 4 dimensions of openness she lays out in the "Openness: Community Members Who Work with Graduate Students" chapter: open minds, open construction of self, open construction of others, and open hearts (Shah 2020: 149-151). She also provides "community grading sheets" with a feedback form so that community partners can give feedback about their experiences working with college students. These tools will be valuable in future community-engaged pedagogy. Perhaps most significant finding for informing future community engaged projects is Shah's concept of critical community-based epistemologies, or ways of knowing, which posits that "community partners are holders and producers of powerful knowledge, and these knowledges can be invaluable in shaping engagement collaborations." (Shah 2020: 107). She argues that this epistemology should both inform the "ethical vision that acknowledges the importance of community member voices, perspectives, and priorities" (109) and the power dynamics so that community partners can hold universities accountable.

Looking forward, there are lessons for future university-community collaborations on environmental justice issues. The university as an institution has a specific positionality, historically and in contemporary power dynamics, but faculty can work in a somewhat different space. Their stakes in the documentation of environmental risks are distinct from corporate and governmental entities, and as such may provide more trusted results than those who rely on the data for profit motives. The university side of the collaboration brings, therefore, the possibility of a counternarrative to the received versions promulgated by government agencies, developers, and industrial representatives. If built on trusted, authentic relationships, these collaborations can also help to amplify the narratives of community perspectives and experiences, but building those relationships is not easy, particularly with the shadow of the university's past and ongoing community harm. The enduring outcomes are also in question. Clearly the intent of those involved is to work for social good, but the actual results are more ambiguous. As Dan Butin and Daniyal Saud wrote in 2013, "what higher education can accomplish through community engagement is an open question rather than an obvious answer.... until and unless we carefully push back on what it is that community engagement can do, there may be little to celebrate a generation from now." (93) For those working for and with IUPUI, the goals of particular community-engaged projects have to be weighed against the broader institutional agendas and actions of the institution, and that balance is precarious at best. In spite of these enduring structural inequalities, the people involved in these projects remain committed to the goals of environmental justice work and to the benefits of community engagement and collaboration. We take inspiration from reflections such as the student who wrote about participating in Climates of Inequality, "[it] made me feel that through the completion of this project, I have actually done something that has made a difference in the world." 


\section{References}

Adair, Bill, Benjamin Filene, and Laura Koloski. Letting Go?: Sharing Historical Authority in a User-Generated World. Philadelphia: The Pew Center for Arts and Heritage, 2011.

Bringle, Robert G., Patti H. Clayton, and Mary F. Price, "Partnerships in Service Learning and Civic Engagement. Partnerships: A Journal of Service Learning and Civic Engagement (2009) 1(1): 1-20.

Butin, Dan W. and Daniyal Saud. Pushing Back the Rhetoric: A Review of What Community Engagement Can Do. Michigan Journal of Community Service Learning, (2013) 19(2), 89-94. Available at: https://scholarworks.merrimack. edu/soe_facpub/10

Climates of Inequality (HAL). https://climatesofinequality.org/

Climates of Inequality (HAL) - Indianapolis https://climatesofinequality.org/story/inequity-along-the-white-river-local-advocacy-for-change/

Climate Justice Alliance, "What Do We Mean By Just Transition?" 2016 https://climatejusticealliance.org/just-transition/ (accessed 8-27-21)

The Cultural Landscape Foundation, Riverside Historic District, https://tclf.org/riverside-drive-historic-district (accessed 8-17-21)

Dumlao, Rebecca. A Guide to Collaborative Communication for Service-Learning and Community Engagement Partners. Stylus, 2018.

Feigenbaum, Paul. "Tactics and Strategies of Relationship-Based Practice: Reassessing the Institutionalization of Community Literacy." Community Literacy Journal (2010-2011) 5 (2): 47- 66.
Green, Jared. "The Power of the 'Four Horsemen of the Livability Apocalypse"" The Dirt: Uniting the Built and Natural Environments. ASLA Blog post, 05/11/2012 https://dirt.asla.org/2012/05/11/ the-power-of-the-four-horsemenof-the-livability-apocalypse/

Humanities Action Lab (HAL) https://www.humanitiesactionlab. org/

Indy Environmental Justice History https://lizkryderreid.wixsite. com/indyejhistory

Indy Environmental Justice History - 2018 student projects: https://lizkryderreid.wixsite.com/ indyejhistory/iupui-student-projects

Jay, Gregory. "The engaged humanities: principles and practices for public scholarship and teaching," Journal of Community-Engagement and Scholarship 3, no 1, 2012: 51-63.

Khalid, Zain. The Four Horsemen of Gentrification, November 3, 2015. https://www.mcsweeneys. net/articles/the-four-horsemen-of-gentrification

Kryder-Reid, Elizabeth. "Dirty Laundry" CHAT (Contemporary and Historical Archaeology in Theory). Festival CHAT Blue Bird Session, October 29, 2020 (https://twitter.com/KryderReid/ status/1323320674774077440

Kryder-Reid, Elizabeth et al. "Environment and Race: Dry Cleaning and Environmental Justice in Indianapolis." StoryMap posted May 26, 2021. https://storymaps.arcgis.com/stories/4d28f320d66e4a449b2bca01e2491b9b

Kryder-Reid, Elizabeth and Paula Brooks. "'A malodorous, septic stream': An environmental justice approach to the architectural history of Indianapolis' urban waterways." Poster Presentation, Society of Architectural Historians Annual Conference Providence, RI (April, 2019). Published as a StoryMap with expanded content (August 2021): https://storymaps.arcgis.com/stories/1a810a7e8d58400ca799f5fdf5cc9355

Kryder-Reid, Elizabeth, Laura M. Holzman, Aghilah Nadaraj, and Leah Humphrey. "Legacies of Environmental Justice in Indianapolis: Collaborative Community Curation" In The City is an Ecosystem: Sustainable Education, Policy, and Practice edited by Margaret Cuonzo, Carole Griffiths, Timothy Leslie, Deborah Mutnick, and Jay Shuttleworth. New York: Routledge, in press.

Longo, Nicholas V. Why Community Matters: Connecting Education with Civic Life. Albany: SUNY Press, 2007.

Lonetree, Amy. Decolonizing Museums Representing Native America in National and Tribal Museums. Chapel Hill: The University of North Carolina Press, 2012.

Mathieu, Paula. "After Tactics, What Comes Next?" In Unsustainable: Re-imagining Community Literacy, Public Writing, Service-learning, and the University, edited by Laurie Cella and Jessica Restaino, 17- 31. Lanham, MD: Lexington Books, 2012.

Mathieu, Paula. Tactics of Hope: The Public Turn in Composition. Portsmouth: Heinemann, 2005.

Parks, Steve. "Strategic Speculations on the Question of Value: The Role of Community Publishing in English Studies." College English (2009) 71 (5): 506- 527

Paschall, Wildstyle. "Indiana Avenue: The Ethnic Cleansing of Black Indianapolis." New America, February 4, 2020. https:// www.newamerica.org/indianapolis/blog/indiana-avenue-ethnic-cleansing-black-indianapolis/
Schwier, Ryan and Peter Elliott "Historical Injustice in the Urban Environment: The Ecological Implications of Residential Segregation in Indianapolis." Published online by the Indiana Legal Archive, (2014) http://www. indianalegalarchive.com/index\#ej-case-study

Shah, Rachael W. Rewriting Partnerships: Community Perspectives on Community-Based Learning. Utah State University Press, 2020.

Toxic Heritage - Collaborative research website. Climates of Inequality Research Project page.https://toxicheritage.com/ research-projects/climates-of-inequality/(Accessed 8-27-2021)

Warren-Gordon, Kiesha. "A Critical Approach to Service-Learning Criminal Justice and Criminology Courses." Collaborations: A Journal of Community-Based Research and Practice, (2021) 4(1): 3, pp. 1-7. DOI: https://doi. org/10.33596/coll.70

Yousry, Farah. This Vegetable Garden Is Also A Safe Haven For Neighborhood Youth Side Effects Public Media. July 8, 2021 https:// www.sideeffectspublicmedia.org/ community-health/2021-07-08/ this-vegetable-garden-is-also-asafe-haven-for-neighborhoodyouth (accessed August 22. 2021). 